\title{
Investigation on Test Anxiety and Coping Style of Middle School Students in Different Nationalities
}

\author{
Qiuyu Hu1 ${ }^{1}$ Qingming $W^{1}{ }^{*}$, Haiping Cheng ${ }^{2}$ \\ ${ }^{1}$ Wuhan University of Science and Technology, Wuhan, China \\ ${ }^{2}$ Qinghai University Medical College, Xining, China

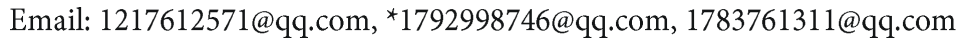

How to cite this paper: $\mathrm{Hu}, \mathrm{Q}$. Y., Wu, Q. M., \& Cheng, H. P. (2018). Investigation on Test Anxiety and Coping Style of Middle School Students in Different Nationalities. Creative Education, 9, 1071-1083. https://doi.org/10.4236/ce.2018.97080

Received: May 7, 2018

Accepted: June 11, 2018

Published: June 14, 2018

Copyright ( $) 2018$ by authors and Scientific Research Publishing Inc. This work is licensed under the Creative Commons Attribution International License (CC BY 4.0).

http://creativecommons.org/licenses/by/4.0/ (c) (i) Open Access

\begin{abstract}
Background: To provide a theoretical basis for formulating effective measures to relieve test anxiety, we understand the current situation of examination anxiety and coping styles of middle school students from different ethnic groups. Methods: A stratified cluster random sampling survey was conducted on 251 junior middle school students in a middle school in Minhe County, Qinghai Province, using the middle school students' test anxiety factors questionnaire (IFTAS) and the middle school students' coping styles scale (CSS). Results: 1) Increasing the grades and ages, the score of different nationalities of middle school students' test anxieties were higher $(F=4.795, P<0.05 ; F=$ $2.468, P<0.05)$; 2) The middle school students' coping style of "pointing to the problem" had statistical significance among grades $(F=6.673, P<0.05)$. 3) "Pointing to emotional response" had statistical significance among the genders in the middle school students $(t=2.421, P<0.05)$. 4) An analysis of the correlation between test anxiety and coping styles among middle school students showed that the relationship between self-esteem and emotional response was highest $(r=0.395, P<0.01) .5)$ The gradual regression analysis of test anxiety and coping style of junior high school students show that "escaping", "seeking social support" and "endurance" were the factors of anxiety of exam in junior high school students. Conclusions: Different national middle school students' test anxiety problems more serious, and most middle school students use "escape" and "seeking social support", "patience" approach. We should guide students to produce the correct coping style.
\end{abstract}

\section{Keywords}

Different Nationality, Middle School Student, Test Anxiety, Coping Style 


\section{Background}

In recent years, the academic pressure of the middle school students is becoming heavier and heavier. Scholars have been paid more and more attention to the students' anxiety and coping styles (Mysorekar, 2012; Sarı, Bilek, \& Çelik, 2017; Liu, Wang, Zhang, et al., 2013). Test anxiety (TA) is a disturbing psychological feeling that a candidate has generated in the examination or exam situation. TA is a kind of contextual trait anxiety (Mysorekar, 2012). Facing the test anxiety situation, examinees are not the same in the context of the corresponding coping style (Sarı, Bilek, \& Çelik, 2017; Shahidi, Akbari, \& Zargar, 2017). However, the study of the middle school students in ethnic areas is more specific than that of other regions (Liu, Wang, Zhang, et al., 2013). And there is relatively little research on the test anxiety and coping style of middle school students. Qinghai Province is a multi-ethnic area. The Minhe Hui Autonomous County in Qinghai Province is dominated by the Han nationality and the ethnic minorities mainly include the Hui, Tu, and Tibetan. And its economy, education, science, technology, culture and health have its unique development model (Ding, Zhang, \& Wang, 2005; Ma, Wang, Li, et al., 2013). Therefore, in order to understand the relationship between test anxiety and coping style of middle school students in ethnic areas, we will formulate an effective coping style to alleviate test anxiety. We investigated the current situation of test anxiety and coping style of secondary school students in Minhe County, Qinghai Province. The findings are as follows.

\section{Materials \& Methods}

\subsection{Participants}

Using the stratified random sampling method, two classes were randomly selected from each grade of junior high school students in Grade 7 to Grade 9 of middle school students in Minhe Hui and Tu Autonomous County, Qinghai Province. A total of 270 students in each class were selected as subjects of study and informed of the purpose and the basic situation of the studying. Students voluntarily participated in the survey and they agreed with the investigator to sign the informed consent form. The middle school had a good representation and represented the Han and ethnic minorities in the Minhe Hui and Tu Autonomous County of Qinghai Province.

\subsection{Methods}

The inventory of influencing factors of test anxiety for secondary school students (IFTAS) (Li, Zhang, \& Wang, 2003) and coping style scale for secondary school students (CSS) (Chen \& Zheng, 2000) were used to conduct a survey by a unified training investigator. Everyone had two-table questionnaires. According to the unified method, the unified training investigator conducted the survey, and organized students to carry out the questionnaire survey in class. The question- 
naires were given out and recycled on the spot, and the students were completed separately.

\subsubsection{Inventory of Influencing Factors of Test Anxiety for Secondary School Students}

IFTAS questionnaire was drawn up by Li yan, Zhang shitong and Wang Jisheng. There were 30 questions and the factors that were used to test the anxiety of junior high school students. The higher the score, the higher the test anxiety.

It consists of five subscales. The first subscale is worrying about academic failure. Subscale 2 is the examination room environment adverse factors. Subscale 3 is the disturbance of an emergency. Subscale 4 is inferiority. Subscale 5 is worrying about the consequences. The questionnaire's Cronbach a coefficient is 0.9467 and the Spearnman-Brown fractional reliability is 0.9366 , indicating that the reliability of the questionnaire is ideal. Exploratory factor analysis found that the factors that affect the test anxiety of middle school students can be explained by 5 factors, and the cumulative contribution rate is $59.7 \%$. Using confirmatory factor analysis, the model's fit index $\chi^{2} / \mathrm{df}=2.36, \mathrm{CFI}=0.928$, ROBUST CFI $=$ 0.939 , indicating that the questionnaire has a good structural validity (Li, Zhang, \& Wang, 2003).

\subsubsection{Coping Style Scale for Secondary School Students}

The questionnaire was used by Chen Shulin who compiled the coping style scale for secondary school students. It is included 36 questions. They were divided into two subscales, which were pointing to the problem and pointing to emotional response. The subscale is composed of solving problem, seeking social support and reasonable positive interpretation. The other subscale consists of endurance, escaping, letting off stream, fantasy and denial. The Cronbach a coefficient of the questionnaire is higher than 0.75 . The Spearnman-Brown fractional reliability is 0.88 . And the retest reliability is 0.89 (Chen \& Zheng, 2000); its validity and reliability are good.

\subsection{Data Analysis}

Using Epidata 3.1 software to establish database and two-way parallel inputs data. SPSS16.0 software was used for statistical analysis. Measurement data using $\mathrm{t}$ test, variance analysis, correlation, stepwise regression and other statistical methods. The test level is taken as $\alpha=0.05$.

\section{Results}

\subsection{General Situation}

A total of 270 questionnaires were issued, and 251 effective questionnaires were collected. Its recovery rate is $92.96 \%$. Among them, boys are 131 , accounting for 52.2\%; Girls are 120, accounting for 47.8\%; The Han nationality had 57 persons, accounting for $22.7 \%$; The Hui nationality had 52 persons, accounting for $20.7 \%$; Tibetans had 58 persons, accounting for $23.1 \%$; The Tu nationality population is 
84, accounting for $33.5 \%$. The population of seventh grade had 93 persons, accounting for $37.1 \%$; and the population of eighth grade had 81 persons, accounting for $32.3 \%$; the population of ninth grade had 77 persons, accounting for $30.7 \%$. The rest is shown in Table 1 .

\subsection{Basic Situation of Examination Anxiety in the Middle School Students}

The test anxiety of the middle school students was not statistically significant between gender and nationality groups ( $t=0.175, P>0.05 ; F=1.280, P>0.05)$.

The middle school students test anxiety in the total test anxiety, worrying about academic failure, the examination room environment adverse factors among the grade groups had statistically significant $(F=4.795, P<0.01 ; F=$ 8.359, $P<0.01 ; F=5.346, P<0.01)$; There was no statistical significance among the grade groups in the disturbance of an emergency, inferiority and worrying about the consequences $(F=0.469, P>0.05 ; F=2.858, P>0.05 ; F=1.160, P>$ 0.05).

Table 1. Basic information of the middle school students.

\begin{tabular}{|c|c|c|c|}
\hline \multicolumn{2}{|c|}{ Variable } & \multirow{2}{*}{$\begin{array}{c}\text { Persons } \\
93\end{array}$} & \multirow{2}{*}{$\begin{array}{c}\text { Composition (\%) } \\
37.1\end{array}$} \\
\hline \multirow{3}{*}{ Grade } & seventh & & \\
\hline & eighth & 81 & 32.3 \\
\hline & ninth & 77 & 30.7 \\
\hline \multirow{2}{*}{ Sex } & boy & 131 & 52.2 \\
\hline & girl & 120 & 47.8 \\
\hline \multirow{6}{*}{ Age } & $\leq 13$ year & 12 & 4.8 \\
\hline & 14 year & 56 & 22.3 \\
\hline & 15 year & 76 & 30.3 \\
\hline & 16 year & 81 & 32.3 \\
\hline & 17 year & 20 & 8.0 \\
\hline & 18 year & 6 & 2.4 \\
\hline \multirow{4}{*}{ Nationality } & Han & 57 & 22.7 \\
\hline & Hui & 52 & 20.7 \\
\hline & Tibetan & 58 & 23.1 \\
\hline & $\mathrm{Tu}$ & 84 & 33.5 \\
\hline \multirow{2}{*}{ Origin of student } & City & 56 & 22.3 \\
\hline & Rural & 195 & 77.7 \\
\hline \multirow{2}{*}{ Only child } & Yes & 16 & 6.4 \\
\hline & No & 235 & 93.6 \\
\hline \multirow{2}{*}{ Extern student } & Yes & 141 & 56.2 \\
\hline & No & 110 & 43.8 \\
\hline
\end{tabular}


In the middle school, there was a statistically significant in total test anxiety, worrying about academic failure, and inferiority among the age groups $(F=$ 2.468, $P<0.05 ; F=2.580, P<0.05 ; F=48.282, P<0.01)$; There was no statistically significant in the examination room environment adverse factors, the disturbance of emergencies, and worrying about the consequences among the age groups $(F=18.082, P>0.05 ; F=9.099, P>0.05 ; F=19.902, P>0.05)$.

In the middle school, there was no statistically significant in the total test anxiety among the Hukou groups $(t=2.143, P>0.05)$, but the "inferiority" dimension was statistical significance $(t=2.015, P<0.05)$. There was no statistical significance difference in other dimensions. See Table 2 for details.

\subsection{The Basic Situation of Coping Style of the Middle School Students}

The middle school students' coping styles in the dimension of pointing to the problem had no statistical significance in gender, age and Hukou groups $(t=$ $1.232, P>0.05 ; F=0.752, P>0.05 ; t=1.781, P>0.05)$.

Coping styles of the middle school students in the dimensions of problem focused coping, problem solving and seeking social support, there was no statistically significant between ethnic groups $(\mathrm{F}=2.572, P>0.05 ; P>0.05 ; \mathrm{F}=1.712$, $\mathrm{F}=1.411, P>0.05)$, but significant in reasonable positive interpretation $(\mathrm{F}=$ 5.788, $P<0.05)$.

Coping style of the middle school students in the dimension of pointing to the problem, problem solving, seeking social support and reasonable positive interpretation were statistically significant among the grade groups $(F=6.673, P<$ $0.01 ; F=4.943, P<0.01 ; F=6.362, P<0.01 ; F=5.788, P<0.01)$. See Table 3 for details.

Coping styles of middle school students in the dimensions of pointing to emotional response was statistically significant between the sex groups $(\mathrm{t}=$ 2.421, $P<0.05)$, but the other factors had no statistical significance.

All factors were not statistically significant in the nationality, grade and $\mathrm{Hu}$ kou groups. $(\mathrm{F}=6.673, P>0.05 ; P>0.05 ; \mathrm{F}=1.562, \mathrm{t}=0.852, P>0.05)$.

The middle school students' coping styles in the dimension of pointing to emotional response had no significant difference among the age groups $(\mathrm{F}=$ 1.463, $P>0.05)$, but letting off stream was significant difference $(\mathrm{F}=42.779, P<$ 0.01 ), and other factors had no significant difference; See Table 4 for details.

\subsection{The Related of the Middle School Students Test Anxiety Factors and Coping Style}

The five dimensions of the test anxiety influencing factors and the responses to the problem and the response to the emotions in the two subscales of the coping style are related. The results were as follows: the five dimensions of the test anxiety influencing factors and the two subscales of the coping style had significant correlation $(P<0.05)$. See Table 5 for details. 
Table 2. Comparison of scores of the middle school students with different characteristics of test anxiety $(\bar{x} \pm \mathrm{s})$.

\begin{tabular}{|c|c|c|c|c|c|c|c|}
\hline Feature & & Total test anxiety & $\begin{array}{c}\text { Worrying } \\
\text { about academic } \\
\text { failure }\end{array}$ & $\begin{array}{l}\text { The examination } \\
\text { room environment } \\
\text { adverse factors }\end{array}$ & $\begin{array}{l}\text { The disturbance } \\
\text { of an emergency }\end{array}$ & Inferiority & $\begin{array}{l}\text { Worrying about } \\
\text { the consequences }\end{array}$ \\
\hline \multicolumn{8}{|l|}{ Sex } \\
\hline & boy & $87.85 \pm 19.51$ & $31.28 \pm 8.04$ & $11.34 \pm 2.78$ & $5.27 \pm 1.93$ & $16.27 \pm 4.50$ & $23.69 \pm 6.20$ \\
\hline & girl & $87.42 \pm 18.65$ & $31.29 \pm 7.24$ & $11.66 \pm 3.31$ & $5.36 \pm 2.10$ & $15.65 \pm 4.51$ & $23.47 \pm 5.72$ \\
\hline & $t$ & 0.175 & 0.010 & 0.832 & 0.359 & 1.084 & 0.302 \\
\hline & $P$ & $>0.05$ & $>0.05$ & $>0.05$ & $>0.05$ & $>0.05$ & $>0.05$ \\
\hline \multicolumn{8}{|c|}{ Nationality } \\
\hline & Han & $86.42 \pm 17.68$ & $31.28 \pm 7.65$ & $10.98 \pm 3.33$ & $5.04 \pm 2.06$ & $15.65 \pm 4.29$ & $23.47 \pm 5.56$ \\
\hline & Hui & $89.06 \pm 17.31$ & $31.63 \pm 6.86$ & $12.00 \pm 2.79$ & $5.25 \pm 2.05$ & $16.23 \pm 4.54$ & $23.94 \pm 5.66$ \\
\hline & Tibetan & $91.12 \pm 20.07$ & $32.50 \pm 8.25$ & $11.84 \pm 3.07$ & $5.57 \pm 1.90$ & $16.67 \pm 4.82$ & $24.53 \pm 6.11$ \\
\hline & $\mathrm{Tu}$ & $85.20 \pm 20.17$ & $30.24 \pm 7.68$ & $11.27 \pm 2.96$ & $5.36 \pm 2.03$ & $15.55 \pm 4.41$ & $22.79 \pm 6.30$ \\
\hline & $F$ & 1.280 & 1.049 & 1.427 & 0.706 & 0.869 & 1.061 \\
\hline & $P$ & $>0.05$ & $>0.05$ & $>0.05$ & $>0.05$ & $>0.05$ & $>0.05$ \\
\hline \multicolumn{8}{|l|}{ Grade } \\
\hline & seventh & $82.86 \pm 18.28$ & $28.80 \pm 7.43$ & $10.74 \pm 2.88$ & $10.74 \pm 2.88$ & $15.33 \pm 4.08$ & $22.84 \pm 5.85$ \\
\hline & eighth & $90.41 \pm 18.18^{a}$ & $32.96 \pm 7.51^{\mathrm{a}}$ & $12.21 \pm 2.66^{\mathrm{a}}$ & $12.21 \pm 2.66^{\mathrm{a}}$ & $15.78 \pm 4.74$ & $24.05 \pm 5.78$ \\
\hline & ninth & $90.52 \pm 19.98^{\mathrm{a}}$ & $32.53 \pm 7.37^{\mathrm{a}}$ & $11.64 \pm 3.42$ & $11.64 \pm 3.42$ & $16.95 \pm 4.63$ & $24.00 \pm 6.28$ \\
\hline & $F$ & 4.795 & 8.359 & 5.346 & 5.346 & 2.858 & 1.160 \\
\hline & $P$ & $<0.01$ & $<0.01$ & $<0.01$ & $<0.01$ & $>0.05$ & $>0.05$ \\
\hline \multicolumn{8}{|l|}{ Age } \\
\hline & $\leq 13$ year & $81.83 \pm 22.20$ & $28.83 \pm 8.56$ & $10.33 \pm 3.17$ & $5.92 \pm 2.06$ & $14.08 \pm 4.72$ & $22.67 \pm 6.57$ \\
\hline & 14 year & $81.66 \pm 19.21$ & $28.68 \pm 8.15$ & $10.80 \pm 3.02$ & $5.16 \pm 2.07$ & $14.80 \pm 3.86$ & $22.21 \pm 6.07$ \\
\hline & 15 year & $88.42 \pm 16.73^{\circ}$ & $31.95 \pm 6.75^{\circ}$ & $11.58 \pm 2.90$ & $5.32 \pm 1.94$ & $15.59 \pm 4.55$ & $23.99 \pm 5.39$ \\
\hline & 16 year & $89.35 \pm 18.90^{\circ}$ & $31.91 \pm 7.56^{\circ}$ & $11.89 \pm 3.03^{\circ}$ & $5.25 \pm 2.05$ & $16.62 \pm 4.22^{\circ}$ & $23.68 \pm 5.96$ \\
\hline & 17 year & $95.65 \pm 22.29^{* *}$ & $34.20 \pm 7.80^{\circ}$ & $11.90 \pm 3.46$ & $5.50 \pm 2.21$ & $18.60 \pm 5.48^{\star \star \star \star}$ & $25.45 \pm 7.37^{\bullet}$ \\
\hline & 18 year & $95.67 \pm 19.08$ & $34.00 \pm 7.80$ & $12.33 \pm 3.01$ & $5.67 \pm 1.12$ & $18.00 \pm 5.14$ & $25.67 \pm 5.16$ \\
\hline & $F$ & 2.468 & 2.580 & 18.082 & 9.099 & 48.282 & 19.902 \\
\hline & $P$ & $<0.05$ & $<0.05$ & $>0.05$ & $>0.05$ & 0.006 & $>0.05$ \\
\hline \multicolumn{8}{|c|}{$\begin{array}{l}\text { Origin of } \\
\text { student }\end{array}$} \\
\hline & City & $77.00 \pm 12.10$ & $27.33 \pm 5.89$ & $10.67 \pm 2.34$ & $5.00 \pm 1.27$ & $12.33 \pm 2.94$ & $21.67 \pm 3.78$ \\
\hline & Rural & $87.91 \pm 19.15$ & $31.38 \pm 7.67$ & $11.51 \pm 3.06$ & $5.32 \pm 2.02$ & $16.06 \pm 4.50$ & $23.63 \pm 6.01$ \\
\hline & $t$ & 2.143 & 1.283 & 0.670 & 0.383 & 2.015 & 0.797 \\
\hline & $P$ & $>0.05$ & $>0.05$ & $>0.05$ & $>0.05$ & $<0.05$ & $>0.05$ \\
\hline
\end{tabular}

Note: compared with the Han ${ }^{\Delta} P<0.05$, compared with the Hui ${ }^{\square} P<0.05$, compared with Tibetan ${ }^{\star} P<0.05$; compared with the seventh grade a $P<0.05$, compared with the eighth grade ${ }^{\mathrm{b}} P<0.05$; compared with $\leq 13$ years old ${ }^{\star} P<0.05$, compared with the 14 -year-old group ${ }^{*} P<0.05$, compared with the 15-year-old group ${ }^{\star} P<0.05$, compared with 16-year-old group ${ }^{\star} P<0.05$, compared with 17-year-old group ${ }^{\diamond} P<0.05$. 
Table 3. Comparison the scores of coping strategies in the coping style of the middle school students with different characteristics $(\bar{x} \pm s)$.

\begin{tabular}{|c|c|c|c|c|c|}
\hline Feature & & Pointing to the problem & Problem solving & Seeking social support & Reasonable positive interpretation \\
\hline \multicolumn{6}{|l|}{ Sex } \\
\hline & boy & $50.53 \pm 7.39$ & $18.82 \pm 3.52$ & $18.32 \pm 3.55$ & $13.39 \pm 2.43$ \\
\hline & girl & $51.79 \pm 8.67$ & $18.61 \pm 3.68$ & $19.16 \pm 3.78$ & $14.02 \pm 2.78$ \\
\hline & $t$ & 1.232 & 0.476 & 1.809 & 1.933 \\
\hline & $P$ & $>0.05$ & $>0.05$ & $>0.05$ & $>0.05$ \\
\hline \multicolumn{6}{|c|}{ Nationality } \\
\hline & Han & $48.96 \pm 8.44$ & $18.09 \pm 3.65$ & $18.02 \pm 3.95$ & $12.86 \pm 2.61$ \\
\hline & Hui & $52.50 \pm 7.65^{\Delta}$ & $18.94 \pm 3.64$ & $19.37 \pm 3.72$ & $14.19 \pm 2.60^{\Delta}$ \\
\hline & Tibetan & $52.53 \pm 7.20^{\Delta}$ & $19.50 \pm 3.43^{\Delta}$ & $19.03 \pm 3.27$ & $14.00 \pm 2.58^{\Delta}$ \\
\hline & $\mathrm{Tu}$ & $50.80 \pm 8.29$ & $18.48 \pm 3.59$ & $18.58 \pm 3.71$ & $13.74 \pm 2.58^{\Delta}$ \\
\hline & $F$ & 2.572 & 1.712 & 1.411 & 2.898 \\
\hline & $P$ & $>0.05$ & $>0.05$ & $>0.05$ & $<0.05$ \\
\hline \multicolumn{6}{|l|}{ Grade } \\
\hline & seventh & $49.23 \pm 8.16$ & $17.86 \pm 3.58$ & $18.39 \pm 3.67$ & $12.98 \pm 2.47$ \\
\hline & eighth & $53.57 \pm 7.24^{\mathrm{a}}$ & $19.52 \pm 3.21^{\mathrm{a}}$ & $19.86 \pm 3.50^{\mathrm{a}}$ & $14.19 \pm 2.42^{\mathrm{a}}$ \\
\hline & ninth & $50.88 \pm 8.10^{\mathrm{b}}$ & $18.92 \pm 3.80$ & $17.92 \pm 3.63^{\mathrm{b}}$ & $14.04 \pm 2.82^{\mathrm{a}}$ \\
\hline & $F$ & 6.673 & 4.943 & 6.362 & 5.788 \\
\hline & $P$ & $<0.01$ & $<0.01$ & $<0.01$ & $<0.01$ \\
\hline \multicolumn{6}{|l|}{ Age } \\
\hline & $\leq 13$ year & $50.25 \pm 8.49$ & $18.08 \pm 3.85$ & $18.58 \pm 3.40$ & $13.58 \pm 2.79$ \\
\hline & 14 year & $52.46 \pm 9.21$ & $18.86 \pm 3.84$ & $19.89 \pm 4.09$ & $13.71 \pm 2.74$ \\
\hline & 15 year & $50.37 \pm 7.86$ & $18.63 \pm 3.42$ & $18.54 \pm 3.64^{*}$ & $13.20 \pm 2.74$ \\
\hline & 16 year & $51.60 \pm 6.52$ & $18.99 \pm 3.23$ & $18.35 \pm 3.36^{\circ}$ & $14.27 \pm 2.39^{\star}$ \\
\hline & 17 year & $49.45 \pm 10.52$ & $18.15 \pm 4.78$ & $17.85 \pm 3.92^{*}$ & $13.45 \pm 3.15$ \\
\hline & 18 year & $49.50 \pm 7.40$ & $18.17 \pm 3.97$ & $18.33 \pm 3.01$ & $13.00 \pm 3.03$ \\
\hline & $F$ & 0.752 & 14.570 & 32.207 & 20.570 \\
\hline & $P$ & $>0.05$ & $>0.05$ & $>0.05$ & $>0.05$ \\
\hline \multicolumn{6}{|c|}{ Origin of student } \\
\hline & City & $46.00 \pm 7.13$ & $16.83 \pm 2.48$ & $17.00 \pm 3.58$ & $12.17 \pm 2.23$ \\
\hline & Rural & $51.26 \pm 8.02$ & $18.77 \pm 3.60$ & $18.76 \pm 3.68$ & $13.73 \pm 2.62$ \\
\hline & $t$ & 1.781 & 1.305 & 1.160 & 1.450 \\
\hline & $P$ & $>0.05$ & $>0.05$ & $>0.05$ & $>0.05$ \\
\hline
\end{tabular}

Note: compared with the Han ${ }^{\triangle} P<0.05$, compared with the Hui ${ }^{\square} P<0.05$, compared with the Tibetan ${ }^{\star} P<0.05$; compared with the seventh grade a $P<$ 0.05 , compared with the eighth grade ${ }^{\mathrm{b}} P<0.05$; compared with $\leq 13$ years old ${ }^{*} P<0.05$, compared with the 14-year-old group ${ }^{*} P<0.05$, compared with the 15-year-old group ${ }^{\star} P<0.05$, compared with 16 -year-old group ${ }^{\star} P<0.05$, compared with 17 -year-old group ${ }^{\diamond} P<0.05$. 
Q. Y. Hu et al.

Table 4. Comparison the response scores of emotional response in the middle school students with different characteristics ( $\bar{x} \pm \mathrm{s})$.

\begin{tabular}{|c|c|c|c|c|c|c|}
\hline Feature & & Pointing to emotional response & endurance & escaping & letting off stream & Fantasy, denial \\
\hline \multicolumn{7}{|l|}{ Sex } \\
\hline & boy & $32.86 \pm 6.51$ & $9.57 \pm 2.35$ & $7.95 \pm 2.53$ & $9.37 \pm 2.52$ & $10.94 \pm 2.98$ \\
\hline & girl & $30.86 \pm 6.59$ & $9.08 \pm 1.96$ & $7.39 \pm 2.43$ & $8.82 \pm 2.29$ & $10.36 \pm 2.82$ \\
\hline & $t$ & 2.421 & 1.783 & 1.767 & 1.830 & 1.583 \\
\hline & $P$ & $<0.05$ & $>0.05$ & $>0.05$ & $>0.05$ & $>0.05$ \\
\hline \multicolumn{7}{|c|}{ Nationality } \\
\hline & Han & $30.91 \pm 6.67$ & $8.70 \pm 2.17$ & $7.65 \pm 2.60$ & $8.65 \pm 2.00$ & $10.49 \pm 3.07$ \\
\hline & Hui & $33.06 \pm 6.80$ & $9.79 \pm 2.05^{\Delta}$ & $7.96 \pm 2.60$ & $9.50 \pm 2.35$ & $11.00 \pm 3.23$ \\
\hline & Tibetan & $32.66 \pm 6.78$ & $9.52 \pm 2.36^{\Delta}$ & $7.67 \pm 2.47$ & $9.52 \pm 2.82$ & $11.03 \pm 2.77$ \\
\hline & $\mathrm{Tu}$ & $31.35 \pm 6.28$ & $9.37 \pm 2.07$ & $7.54 \pm 2.40$ & $8.89 \pm 2.40$ & $10.31 \pm 2.68$ \\
\hline & $F$ & 1.412 & 2.541 & 0.315 & 1.931 & 1.026 \\
\hline & $P$ & $>0.05$ & $>0.05$ & $>0.05$ & $>0.05$ & $>0.05$ \\
\hline \multicolumn{7}{|l|}{ Grade } \\
\hline & seventh & $32.48 \pm 6.75$ & $9.55 \pm 2.04$ & $7.78 \pm 2.55$ & $9.05 \pm 2.37$ & $10.89 \pm 2.80$ \\
\hline & eighth & $32.28 \pm 6.24$ & $9.41 \pm 1.96$ & $7.72 \pm 2.45$ & $9.35 \pm 2.37$ & $10.99 \pm 3.03$ \\
\hline & ninth & $30.81 \pm 6.77$ & $9.01 \pm 2.53$ & $7.52 \pm 2.50$ & $8.92 \pm 2.54$ & $10.04 \pm 2.85$ \\
\hline & $F$ & 1.562 & 1.333 & 0.249 & 0.639 & 2.592 \\
\hline & $P$ & $>0.05$ & $>0.05$ & $>0.05$ & $>0.05$ & $>0.05$ \\
\hline \multicolumn{7}{|l|}{ age } \\
\hline & $\leq 13$ year & $32.50 \pm 6.90$ & $10.08 \pm 2.61$ & $7.75 \pm 2.14$ & $8.42 \pm 2.91$ & $11.08 \pm 2.71$ \\
\hline & 14 year & $30.70 \pm 6.52$ & $9.46 \pm 2.29$ & $7.27 \pm 2.47$ & $8.36 \pm 2.19$ & $10.23 \pm 2.85$ \\
\hline & 15 year & $33.25 \pm 6.53^{*}$ & $9.32 \pm 1.81$ & $8.04 \pm 2.30$ & $9.64 \pm 2.13^{\circ}$ & $11.26 \pm 3.03^{\circ}$ \\
\hline & 16 year & $31.99 \pm 6.59$ & $9.40 \pm 2.28$ & $7.64 \pm 2.49$ & $9.49 \pm 2.47^{\circ}$ & $10.56 \pm 2.94$ \\
\hline & 17 year & $30.20 \pm 6.80$ & $8.60 \pm 2.11$ & $7.90 \pm 3.31$ & $8.25 \pm 2.81^{\star \Delta}$ & $10.00 \pm 2.71$ \\
\hline & 18 year & $29.50 \pm 6.38$ & $8.67 \pm 3.39$ & $6.67 \pm 2.94$ & $8.33 \pm 3.08$ & $9.83 \pm 2.04$ \\
\hline & $F$ & 1.463 & 16.570 & 15.864 & 42.779 & 19.159 \\
\hline & $P$ & $>0.05$ & $>0.05$ & $>0.05$ & $<0.01$ & $>0.05$ \\
\hline \multicolumn{7}{|c|}{ Origin of student } \\
\hline & City & $30.00 \pm 5.51$ & $8.83 \pm 2.48$ & $7.17 \pm 3.06$ & $8.83 \pm 2.48$ & $10.33 \pm 2.42$ \\
\hline & Rural & $31.95 \pm 6.64$ & $9.35 \pm 2.18$ & $7.69 \pm 2.49$ & $9.35 \pm 2.18$ & $10.67 \pm 2.93$ \\
\hline & $t$ & 0.852 & 0.574 & 0.511 & 0.280 & 0.279 \\
\hline & $P$ & $>0.05$ & $>0.05$ & $>0.05$ & $>0.05$ & $>0.05$ \\
\hline
\end{tabular}

Note: compared with the Han ${ }^{\triangle} P<0.05$, compared with the Hui ${ }^{\square} P<0.05$, compared with the Tibetan ${ }^{\star} P<0.05$; compared with the seventh grade a $P<$ 0.05 , compared with the eighth grade ${ }^{\mathrm{b}} P<0.05$; compared with $\leq 13$ years old ${ }^{\star} P<0.05$, compared with the 14-year-old group ${ }^{*} P<0.05$, compared with the 15-year-old group ${ }^{\star} P<0.05$, compared with 16-year-old group ${ }^{\star} P<0.05$, compared with 17-year-old group ${ }^{\diamond} P<0.05$. 
Table 5. Correlation analysis of two subscales of test anxiety factors and coping styles of Junnior middle school students.

\begin{tabular}{cccc}
\hline variable & $\begin{array}{c}\text { Correlation } \\
\text { coefficient }\end{array}$ & $\begin{array}{c}\text { Pointing to the } \\
\text { problem }\end{array}$ & $\begin{array}{c}\text { Pointing to } \\
\text { emotional response }\end{array}$ \\
\hline Worrying about academic failure & $r$ & 0.304 & 0.264 \\
Adverse factors in the examination & $P$ & 0.000 & 0.000 \\
room environment & $P$ & 0.264 & 0.272 \\
The disturbance of an emergency & $r$ & 0.000 & 0.000 \\
Inferiority & $P$ & 0.253 & 0.214 \\
& $r$ & 0.000 & 0.001 \\
& $P$ & 0.129 & 0.395 \\
Worrying about the consequences & $r$ & 0.041 & 0.000 \\
& $P$ & 0.204 & 0.348 \\
\hline
\end{tabular}

Table 6. Test scores of the total score and coping style of test anxiety.

\begin{tabular}{cccccc}
\hline Factor & B & SE & Beta & $t$ & $P$ \\
\hline Constant term & 36.661 & 7.031 & & 5.214 & 0.000 \\
Escaping & 2.067 & 0.462 & 0.271 & 4.479 & 0.000 \\
Seeking social support & 1.231 & 0.300 & 0.238 & 4.098 & 0.000 \\
Endurance & 1.292 & 0.537 & 0.148 & 2.407 & 0.017 \\
\hline
\end{tabular}

\subsection{Stepwise Regression Analysis of Influencing Factors of Test Anxiety and Coping Style of the Middle School Students}

The test anxiety total score as the dependent variable and coping style as the independent variables get on multiple stepwise regression analysis. "Escaping", "seeking social support" and "endurance" come into the regression equation, which can explain the variance of $20.18 \%$ of the total test anxiety variance. See Table 6 for details.

\section{Discussion}

\subsection{Differences in Basic State of Test Anxiety among Middle School Students of Different Nationalities}

There were no significant differences in gender, nationality and household registration among the middle school students in ethnic areas, but there was significant difference in grade and age groups. With the increasing grades, the test anxiety is also getting higher and higher (Voltas, Hernándezmartínez, Arija, et al., 2017). Since the students of grade seven had just entered the middle school campus, they had a good yearning for the life of the middle school. And they had not yet felt the learning pressure of junior middle school, so their test anxiety scores are the lowest; Because the students of grade eight were increasing their 
learning tasks and facing final placement exams, they may be more anxious than students of grade seven; Because the ninth-grade students often face various mock exams and the pressure of senior high school entrance examination, they are more anxious than those of grade seven and grade eight.

With the increasing of age, the middle school students test anxiety was stronger. In particular, the scores of "worrying about academic failure" and "worrying about the consequences" increased with age. The educational level of ethnic areas is lower than that of other areas, leading to the age of children going to school more than that of other areas. At the same time, the older junior middle school students bear the social and family pressure than the younger junior middle school students, leading to higher scores than the younger junior middle school students' test anxiety (Zhou, Yang, Yu, et al., 2017).

The inferiority of middle school students in ethnic minority areas had significant differences between urban and rural areas. Because the majority of students come from rural areas in ethnic areas, the educational environment and cultural environment were relatively backward (Condon, Worley, Condon, et al., 2017). In order to change their present situation, the stress of students in rural areas was more than that of students in urban areas, which lead to relatively high examination anxiety. Countries need to increase investment in education in rural areas, improving the learning environment for students in rural areas and increasing students' self-confidence (Czajka, Fiszer, \& Kołodziej, 2013).

\subsection{Differences in the Basic State of Coping Style among Middle School Students of Different Nationalities}

The coping style of middle school students in the dimension of pointing to problem had significant difference among grade groups in the minority areas. Students in grade eight often adopted more positive coping styles than those in grade seven and grade nine. Probably because the students of grade seven have just entered the middle school, they were relatively unfamiliar with the learning environment of junior middle school, and didn't know how to solve their own problems. The students of grade eight were gradually familiar with the school life environment, and choose more positive coping styles. The students of grade nine were faced with high school entrance examinations, so the teachers and parents had too much concern for their children, which maybe cause the students of grade nine to choose positive coping styles less than those of grade eight. Psychological counseling should be carried out regularly to solve the psychological problems of students in time, and help students master some methods to control emotions, and learn to regulate their emotions independently (Okuyama, Funakoshi, Tomita, et al., 2017).

The results of this study showed that the Hui, Tibetan and Tu have higher scores in pointing to the problem, solving problems, and actively rationalizing the interpretation than the Han nationality. It may be the state's strong support for ethnic minorities, as well as the customs, religious beliefs and living envi- 
ronment of Hui, Tibetans and Han nationality (Arthur, Brown, John, et al., 2015). At the same time, the Han population was a relatively large proportion of the population, and the pressure on the ethnic minorities was greater than that of other ethnic minorities, resulting in a different coping style between Han and ethnic minorities in the face of test anxiety.

The study showed that boys had a higher score of "pointing to emotional response" than girls. It may be that girls' psychological development is earlier than boys', making them more rational and mature than boys in dealing with examinations and other problems (Y1lmaz, Aksel, \& Thompson, 2016). In the ethnic areas of Qinghai Province, the "patriarchal" ideology is still more serious. So this leads to many boys becoming more dependent on their families than girls. In the face of difficulties, they do not know how to deal with them independently. When they fail in the exam, they may suffer from "endurance", "escape", "let off stream" and "fantasy, denial" and other psychological problems (Guilmoto, 2017). Therefore, parents should pay attention to the ability to cultivate children's independent life and the courage to face setbacks

In the "endurance" dimension, the Tibetan and Hui nationality of junior middle school students scored higher than the Han nationality. The Hui people spent one month on Ramadan, and they prayed five times every day, while the Tibetan people believed in Buddhism whether in the conditions of hardship or superior conditions. It may be contributed to the living habits of the ethnic areas.

The pointing to emotional response of middle school students in the dimension of "letting off stream" had a significant difference among the age groups. 15-year-old junior high school students scores are significantly higher than those of other age groups. Maybe the junior middle school students of this age are just in the period of youth rebellion. When facing difficulties, they don't know how to deal with the problems, and they often choose to let off stream to relieve the pressure. And individuals of different ages have differences in cognitive level, feeling ability, life experience, behavior habits and so on; It inevitably leads to different coping styles when facing or dealing with stress and frustration, and it is related to the development and change of self-consciousness development with age (Arthur, Brown, John, et al., 2015).

\subsection{The Relationship between Test Anxiety and Coping Style among Middle School Students of Different Nationalities}

There were significant positive correlations between the two factors of test anxiety and coping style, which indicated that junior high school students had an interaction with the test anxiety of influencing factors and selection of coping style (He, Zhao, Cao, et al., 2010). The scores of each dimension were higher in the factor of test anxiety, and the scores of pointing to the problem and pointing to the emotional response were higher in the chosen coping style. Further regression analysis showed that students made too much fear of the exam and too 
much imagination of the examination situation, so that tension led to test anxiety increasing. Gradual regression survey results showed that most of the methods used by students are "escaping", "seeking social support" and "endurance". Students should do their best to study hard, do the preparatory preparation before the class and do prepare for review the lessons after the class. When students didn't understand problems, they should ask the teacher, classmates, parents or access to books to solve the problems and carefully complete the task of teacher arrangement, Careful reviewing before examination, calmly facing the exam, students can reduce the test anxiety. Students need to use positive coping styles to face test anxiety, constantly adjust their mentality, and turn negative coping styles into positive coping styles (Mcconnell, Memetovic, \& Richardson, 2014).

\section{Conclusion}

We found that there is a positive correlation between the scores of test anxiety and the two dimensions of coping style of the middle school students in minority areas. And the stepwise regression analysis of the middle school students' test anxiety and coping style showed that "avoiding", "seeking social support" and "endurance" were the impact of factors of test anxiety of junior high school students. Therefore, we need to attach importance to the psychological state of the junior high school students exams, and guide the students to cultivate the correct behavior.

\section{Ethical Considerations}

Ethical issues (Including plagiarism, informed consent, misconduct, data fabrication and/or falsification, double publication and/or submission, redundancy, etc.) have been completely observed by the authors.

\section{Acknowledgements}

This research was not funded by any unit. We acknowledge all the school students and all researchers for their dedication and commitment to this research.

\section{Conflicts of Interest}

The authors declare that there is no conflict of interest.

\section{References}

Arthur, M. W., Brown, E. C., John, M. A., et al. (2015). Examination of Substance Use, Risk Factors, and Protective Factors on Student Academic Test Score Performance. Journal of School Health, 85, 497-507. https://doi.org/10.1111/josh.12279

Chen, S. L., \& Zheng, Q. Q. (2000). Copying Style Scale for Secondary School Students. Chinese Journal of Clinical Psychology, 8, 211-214.

Condon, B. P., Worley, P. S., Condon, J. R., et al. (2017). Student Academic Performance in Rural Clinical Schools: The Impact of Cohort Size and Competition. Medical Teacher, 39, 262-268. https://doi.org/10.1080/0142159X.2017.1270430 
Czajka, K., Fiszer, K., \& Kołodziej, M. (2013). The Relation between Selected Health Behaviour and Body Mass Index amongst Adolescents Living in Urban and Rural Areas in South-Western Poland. Roczniki Państwowego Zakładu Higieny, 64, 135-141.

Ding, S. X., Zhang, H. Y., \& Wang, X. P. (2005). An Analysis on the Social-Economic Development Status of Qinghai Province. Economic Geography, 25, 495-498.

Guilmoto, C. Z. (2017). Gender Bias in Reproductive Behaviour in Georgia, Indonesia, and Vietnam: An Application of the Own-Children Method. Population Studies, 71, 1-15. https://doi.org/10.1080/00324728.2017.1330489

He, X. Y., Zhao, G. Q., Cao, R. F., et al. (2010). Canonical Analysis between Mental Health and Coping Style Variables of Middle School Students. Chinese Journal of Public Health, 26, 745-747.

Li, Y., Zhang, S. T., \& Wang, J. S. (2003). Questionnaire of Influencing Factors of Middle School Students' Test Anxiety. Psychological Science, 2, 352-354.

Liu, S., Wang, Z. F., Zhang, F. B., et al. (2013). Associations of Negative Life Events and Coping Style with Health Conditions among Medical Students in Minority Ethnic Region. Chinese Journal of Public Health, 29, 1034-1038.

Ma, J., Wang, Y. B., Li, K., et al. (2013). Polymorphisms of 21 Short Tandem Repeat Loci of Salar Minority Ethnic Group in Qinghai Province. Acta Academiae Medicinae Sinicae, 35, 535-541.

Mcconnell, M. M., Memetovic, J., \& Richardson, C. G. (2014). Coping Style and Substance Use Intention and Behavior Patterns in a Cohort of BC Adolescents. Addictive Behaviors, 39, 1394-1397. https://doi.org/10.1016/j.addbeh.2014.05.018

Mysorekar, V. V. (2012). Need for Mentorship to Improve Learning in Low-Performers. National Medical Journal of India, 25, 291-293.

Okuyama, J., Funakoshi, S., Tomita, H., et al. (2017). School-Based Interventions Aimed at the Prevention and Treatment of Adolescents Affected by the 2011 Great East Japan Earthquake: A Three-Year Longitudinal Study. Tohoku Journal of Experimental Medicine, 242, 203-213. https://doi.org/10.1620/tjem.242.203

Sarı, S. A., Bilek, G., \& Çelik, E. (2017). Test Anxiety and Self-Esteem in Senior High School Students: A Cross-Sectional Study. Nordic Journal of Psychiatry, 72, 84-88. https://doi.org/10.1080/08039488.2017.1389986

Shahidi, S., Akbari, H., \& Zargar, F. (2017). Effectiveness of Mindfulness-Based Stress Reduction on Emotion Regulation and Test Anxiety in Female High School Students. Journal of Education and Health Promotion, 6, 87. https://doi.org/10.4103/jehp.jehp_98_16

Voltas, N., Hernándezmartínez, C., Arija, V., et al. (2017). The Natural Course of Anxiety Symptoms in Early Adolescence: Factors Related to Persistence. Anxiety Stress \& Coping, 30, 671. https://doi.org/10.1080/10615806.2017.1347642

Yılmaz, I. T., Aksel, Ş., \& Thompson, D. (2016). Coping Strategies and Depression among College Students Following Child Sexual Abuse in Turkey. Journal of Child Sexual Abuse, 25, 881-894. https://doi.org/10.1080/10538712.2016.1236871

Zhou, J., Yang, J., Yu, Y., et al. (2017). Influence of School-Level and Family-Level Variables on Chinese College Students' Aggression. Psychology, Health \& Medicine, 22, 823-833. https://doi.org/10.1080/13548506.2016.1237667 